\title{
Reparações, direitos humanos e cidadania: uma gramática para o conflito racial no Brasil?
}

\author{
Reparations, human rights and citizenship: \\ a grammar for racial conflict in brazil?
}

\section{Flavia Rios ${ }^{2}$}

SAILlant, Francine. Le mouvement noir au Brésil (2000-2010): Réparations, droits et citoyenneté. Collection Anthropologie prospective. France: Academia L'Harmattan S.A, 2014.

A antropóloga Francine Saillant ofereceu ao público de língua francesa um vibrante panorama das relações raciais brasileiras contemporâneas, deixando em relevo as ações e os discursos de grupos e indivíduos que buscam romper com as representações depreciadas sobre a população negra. Todavia, o trabalho da autora não se resume a uma apresentação cuidadosa do histórico dos conflitos e das reivindicações de descendentes de africanos no país. O livro também tem algumas contribuições originais para o campo de estudo das relações raciais, especialmente no que toca à mobilização coletiva negra da última década.

O primeiro êxito da pesquisadora foi seu recorte histórico. Concentrar sua investigação na primeira década do século XXI ofereceu uma perspectiva inovadora sobre o tema proposto. É fato que a literatura acadêmica brasileira, assim como as avaliações dos ativistas, mostraram enfaticamente a inflexão no debate sobre as questões étnico-raciais no Brasil após o processo da III Conferência contra o racismo, ocorrida na cidade sul-africana de Durban em 2001. Já era um consenso, entre nós pesquisadores brasileiros, que a conferência foi um grande divisor de águas para a política antirracista, sendo possível até mesmo falar de um Brasil antes e depois desse conclave mundial do início do milênio. Mas também é fato que essas mudanças ocorridas a partir da última década estão longe de possibilitar um diagnóstico de conjunto capaz de mostrar a complexidade das transformações em curso. Parte dessas mudanças pode ser atribuída às transformações culturais vivenciadas pela sociedade no que toca à questão racial; outra parte está diretamente relacionada à forma pela qual essa temática adentrou o espaço institucional. Contudo, o foco da análise da antropóloga não é exatamente o Estado e as políticas

a Flavia Rios é professora de Sociologia da UFG. 
de inclusão voltadas para o segmento negro da população brasileira. Seu interesseé, antes, a agência dos grupos, das instituições e dos indivíduos comprometidos com o combate ao racismo. Sendo assim, não se trata apenas de um estudo circunscrito ao movimento negro, no sentido nativo do termo, mas de uma investigação que busca revelar uma rede complexa, envolvendo múltiplos agentes civis, religiosos, políticos e culturais atuantes em diferentes níveis e pontos do tecido social, tendo como horizonte um reconhecimento adequado da representação coletiva em diferentes esferas da sociedade.

A disputa pela representação social e as reivindicações por direitos não são formas apartadas de fazer política. Essa é a aposta intelectual do livro Le mouvement noir au Brésil (2000-2010): Réparations, droits et citoyenneté, publicado em 2014 e vendido nas livrarias do Canadá e da França. Fazer política é também fazer cultura, e o inverso também se apresenta como par complementar - e não oposto - na interpretação de Saillant sobre a sociedade brasileira. Ao desfazer esse nó, a autora se livra de grande parte dos problemas que enviesaram a recepção nacional de trabalhos feitos por pesquisadores estrangeiros, a exemplo do cientista político norte-americano, Michel Hanchard (1994).

Com efeito, o trabalho da autora é um convite atraente para quem quer conhecer um Brasil em mudança. Sem estereótipos e figurações oficiais, a antropóloga acompanha as reflexões das ciências sociais brasileiras, incluindo a historiografia nacional que lhe serve de baliza nos capítulos em que oferece ao público estrangeiro uma perspectiva sócio-histórica da formação nacional do país sul-americano. Isso é particularmente notável no primeiro capítulo do livro, intitulado "Esclavage et question noire au Brésil". Neste, a autora não apenas prepara as lentes do leitor leigo nos assuntos brasileiros, como também constrói o problema de sua pesquisa, qual seja, a relação entre reparação, direitos humanos e cidadania. Reparar não seria uma simples "correção" do passado escravista, mas sobretudo reestabelecer outras narrativas da História dos africanos e seus descendentes no Brasil. Seria levar em consideração tanto a experiência social da escravidão quanto os legados relativos à sua desumanização no tempo passado e presente, bem como as justificações e estratégias usadas pelos agentes da resistência negra no combate às desigualdades e às discriminações de cunho raciais, que, para tanto, disputam sua autorrepresentação em contraste com a representação dominante, de feição colonial.

Um dos pontos nevrálgicos que atualiza os legados nefastos da escravidão é o problema da violência contra a população negra, particularmente contra o segmento masculino desse grupo. Fonte de protestos no Brasil, a violência letal que 
gera índices elevadíssimos de mortalidade juvenil entre os homens pretos e pardos é tema do segundo capítulo do livro. Embora seja pauta antiga para a militância brasileira, o problema da violência racial tem presença oscilante e ambígua nas ciências sociais. Nos estudos das relações raciais, a violência física é tema marginal; na sociologia que se especializou em violência, raça é apenas um dos descritores do perfil das vítimas. Trabalhos empíricos sobre o tema ganharam incremento na última década, mas estão longe de ganhar posição relevante na academia brasileira. No capítulo "Brésil, violences et droits humains: classe, race et heritages de l'histoire", a antropóloga destaca o ativismo que luta para pôr em evidência o viés racial da mortalidade externa que atinge fortemente os jovens negros brasileiros, especialmente, aqueles que habitam as periferias dos grandes centros urbanos. A autora nota o empenho das lideranças civis em tornar a questão da violência letal um problema de direitos humanos e, ao olhar arguto da pesquisadora, não escapa a estratégia acertada do ativismo de elevar o tema da violência para além das fronteiras nacionais, já que o Estado é um dos alvos da crítica negra.

À mobilização política e seu histórico no país, a autora dedica dois capítulos - "Des révoltes coloniales au mouvement noir contemporain émancipations et réparations" e "Promouvoir la mémoire et la culture afro-brésilienne"- nos quais faz uma revisão bibliográfica sem alterar as periodizações já estabelecidas pela literatura nacional. Tal como o historiador Clóvis Moura, a professora da Université Laval retoma as formas de resistência à escravidão e firma seu alicerce num histórico dos movimentos negros, destacando as suas formas organizativas mais famosas, a exemplo da Frente Negra Brasileira (FNB), nos anos trinta; o Teatro Experimental do Negro (TEN), no pós-segunda guerra mundial; e, por fim, o Movimento Negro Unificado (MNU), emergente no processo de abertura política no contexto da ditadura militar (MourA, 1983). A autora, embora não traga nenhuma novidade em termos de fontes e de interpretação para aqueles períodos, faz bem ao retraçar esses ciclos de mobilização porque está escrevendo para um público que tem pouco conhecimento das formas de ação coletiva negra durante o século XX. É que o livro Le mouvement noir au Brésil, apesar de seu recorte temporal na primeira década do novo milênio, se apresenta como uma densa e atual referência sobre a estrutura e o significado do conflito racial no Brasil, no que se refere às disputas por representação e direitos, levando em conta as heranças culturais, políticas e sociais da escravidão.

Nesse sentido, o processo da organização da Conferência de Durban enquadra a atenção da pesquisadora. Nele, a autora sublinha as pré-conferências, assim como os resultados advindos do grande encontro acontecido na África do Sul. Dedica- 
-se a entender as articulações das lideranças brasileiras em fóruns internacionais, a exemplo do encontro preparatório em Santiago, no Chile, onde a presença da delegação brasileira, civil e governamental, já se mostrava influente e expressiva. Francine Saillant destaca as lutas dos ativistas por tornar a escravidão um crime contra a humanidade, assim como as demandas por ampliação da cidadania nos estados nacionais. Não por acaso, o ativismo brasileiro, com protagonismo das mulheres negras, defendeu com afinco as chamadas affirmative actions. Estas se inseriram na linguagem jurídica nacional e foram decisivas para a ampliação das legislações, dos órgãos estatais e das políticas de igualdade racial. Para a antropóloga, tanto as demandas por reconhecimento da história da escravização humana, e suas sequelas para seus descendentes, como as políticas públicas de Estado são entendidas na chave das reparações. Sendo assim, essas reparações tornam-se, então, um conceito que abrange tanto reinvindicações de caráter redistributivo como as de natureza simbólica e jurídica.

Da política à arte, a pesquisadora dedica um capítulo inteiro à produção artística afro-brasileira contemporânea. Sob o título "Réparer par l`art: pratiques et perspectives d'artistes engagés”, o capítulo cinco trata da relação dos artistas com o movimento negro. Ao contrário dos estudos que a precederam, Saillant não se limita a mostrar a importância da música e da indústria fonográfica para a difusão de mensagens de orgulho ou de autoafirmação racial. Ela pesquisa outras formas artísticas com e sem interface direta com a indústria de entretenimento. Seu interesse recai sobre as artes visuais (fotografia, escultura, cinema e pintura) e performáticas (o teatro, a dança). Trata-se do capítulo mais original do livro, porque analisa uma gama expressiva de concepções, práticas e trajetórias - a exemplo dos cineastas Zózimo Bulbul e Zoel Zito Araújo, dos fotógrafos Januário Garcia e Valter Firmo, dos artistas ligados às artes cênicas Carmen Luz, Rubens Barbot e Hilton Cobra - e mostra no detalhe como a produção artística pode estar atrelada ao engajamento político sem que aquela perca o status de arte ${ }^{1}$.

Não apenas os artistas, seus discursos e obras são objetos de análise em Le mouvement noir au Brésil, mas também as instituições e organizações que possuem em sua missão a preservação da memória material e imaterial dos afro-brasileiros, como os museus e os acervos públicos e comunitários. Embora concentrada exclusivamente no Rio de Janeiro, Saillant deixa uma janela aberta para que estudos futuros venham investigar a presença e articulação dos artistas

1 Contudo, faltaram à análise trabalhos nacionais que muito teriam contribuído para uma crítica mais refinada sobre a interface entre política e arte, a exemplo da pesquisa de Carvalho, 2005. 
e curadores negros na construção de uma representação antirracista em outras partes do país.

Dos oito capítulos que compõem Le mouvement noir au Brésil (2000-2010), Francine Saillant dedica dois ao tema da religiosidade e suas relações com a mobilização negra. Em "Religions, racisme et discriminations" e " Le candomblé: lieu de mémoire et d'affirmation”, a religiosidade e seu hibridismo é extremamente relevante para a construção do argumento da autora. Isso porque ela nota, assim como fez Roger Bastide nos anos iniciais da década de 1970, a relevância da cultura de matriz africana e seu sincretismo para a construção da identidade coletiva negra contemporânea (BASTIDE, 1976). O sentimento de pertencimento a uma comunidade se faz e se refaz na interface com a religiosidade. Todavia, tal construção não acontece de maneira simplista e a autora nota bem isso. Não é apenas o candomblé e os demais terreiros de crenças afro-brasileiras que nutrem o sentimento de comunidade negra, mas a própria religião católica no veio da teologia da libertação - a exemplo das pastorais afro - atua diretamente na constituição da identidade coletiva que irá marcar a mobilização negra contemporânea.

Nesse sentido, a incursão etnográfica da autora no município de São João do Meriti, região periférica da área metropolitana do Rio de Janeiro, traz um ganho significativo ao trabalho. As narrativas da Mãe Torody e dos Freis Davi e Tatá são exemplares para evidenciar as formas organizativas nas periferias urbanas diretamente atreladas à luta por sobrevivência religiosa e social dos afrodescendentes. As inscrições racializadas no território são flagrantes, seja na exclusão territorial, seja na ocupação pública da luta antirracista, via cursinhos pré-vestibulares, eventos de combate ao racismo, fortalecimento de terreiros de candomblé ou mesmo as missas afro na confluência inter-religiosa. Todos esses fatores marcam a interação entre cultura e política.

O uso instrumental da religiosidade bem como a experiência subjetiva religiosa são duas faces para a consolidação do movimento negro no Brasil. Não é uma relação fácil nem tranquila, mas há que se notar cada vez mais um estreitamento das relações entre a política e a religião, principalmente quanto à sua eficácia para a articulação que visa barrar a intolerância religiosa, vinda, em especial, das denominações neopentecostais. Tal articulação também tornou-se importante porque criou condições de ampliação da cidadania a jovens pobres e negros, mostrando-lhes horizontes alternativos à acomodação social. Exemplos expressivos disso são os projetos coletivos enraizados socialmente cuja potência foi decisiva para manter e subsidiar as lutas por ações afirmativas no ensino de terceiro grau. 
Em “Réparation, justice et devenir des afro-brésiliens”, capítulo derradeiro e de balanço analítico, a autora se indaga se o Brasil não teria, diante de todo esse histórico de mobilização e aquisições culturais e políticas, uma lição a ensinar para grupos minoritários que reivindicam igualdade ao redor do mundo. Dessa feita, se tratariam de "réparations à la brésilienne”, seja numa concepção jurídica ou numa perspectiva antropológica dos direitos humanos. No conjunto, Saillant nos convence do quão eloquente é a presença do tema da escravidão para os discursos de justificação da igualdade no ativismo contemporâneo.

A leitura de Le mouvement noir au Brésil é interessante do começo ao fim. Aliás, nenhum leitor deixará de notar a bela introdução do livro que nos conduz a um cenário urbano e repleto de simbologias da resistência afro-brasileira. É a marcha noturna, que acontece há quase duas décadas no centro de São Paulo, às vésperas do treze de maio. Na caminhada litúrgica embalada por canções religiosas e profanas, ativistas, religiosos de diferentes denominações, artistas e políticos marcham pelas ruas do centro da maior metrópole brasileira. Em seus discursos, a luta contra o racismo se insere na gramática dos conflitos sociais flagrada na linguagem analítica das reparações, da cidadania e dos direitos humanos. A interpretação canadense sobre o conflito racial no Brasil se introduz, assim, no seleto grupo dos bons trabalhos estrangeiros sobre a mobilização negra nacional, no qual já figuram nomes como o de Michel Mitchell, Michel Hanchard, Kim Butler e Paulina Alberto, para ficar com os pesquisadores mais conhecidos entre nós.

\section{REFERÊNCIAS BIBLIOGRÁFICAS}

BASTIDE, Roger. Negritude et integration nationale. Afro-Ásia. N. 12, p. 17-30. 1976.

Carvalho, Noel. Cinema e representação racial: cinema negro de Zózimo Bulbul. Tese (doutorado). Faculdade de Filosofia, Letras e Ciências Humanas da Universidade de São Paulo. São Paulo, 2005.

Hanchard, Michel. Orpheus and Power: The Movimento Negro of Rio de Janeiro and São

Paulo, Brazil 1945-1988. Princeton: Princeton University Press, 1994.

Moura, Clóvis. Brasil: Raízes do protesto negro. São Paulo: Global, 1983.

SAILlant, Francine. Le mouvement noir au Brésil (200O-2010): Réparations, droits et citoyenneté. Collection Anthropologie prospective. France: Academia L'Harmattan S.A, 2014 . 